\title{
Die Entwicklung der Rechtskraftlehre im französischen und spanischen Recht
}

\author{
Eine rechtsvergleichende Untersuchung
}

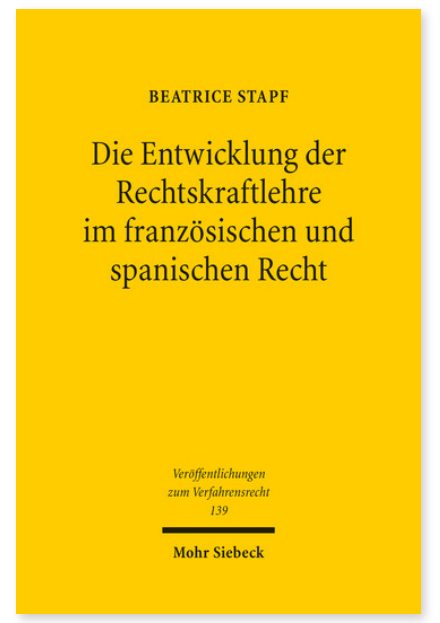

2017. XXIX, 679 Seiten. VVerfR 139

ISBN 978-3-16-155088-1

DOI 10.1628/978-3-16-155088-1

eBook PDF 114,00€

ISBN 978-3-16-155056-0 fadengeheftete Broschur 114,00€

Als Rechtssicherheit und Rechtsfrieden stiftende Wirkung gerichtlicher Streitentscheidung stellt die Rechtskraft eines der zentralen Institute des Zivilprozessrechts dar. Gerade in Frankreich und Spanien hat die Rechtskraftdogmatik in den letzten Jahren erhebliche Veränderungsprozesse durchlaufen. Beatrice Stapf widmet sich einer vertieften Analyse der Entwicklungen der Rechtskraftlehre in Frankreich und Spanien und verortet diese rechtsvergleichend in einem gesamteuropäischen Rahmen. Dabei beschreibt sie nicht nur den gegenwärtigen Stand der französischen und spanischen Rechtskraftlehre, sondern vollzieht auch den Prozess der Entwicklung hin zum derzeitigen Rechtszustand nach. Auf diese Weise werden Entwicklungstendenzen einer aktuellen Rechtskraftdogmatik identifiziert, die auch für eine künftige europäische Rechtsentwicklung bedeutsam sein könnten.

Die Arbeit wurde mit dem Carl-von-Rotteck-Preis 2016 ausgezeichnet.

Beatrice Stapf Geboren 1984; Studium der Rechtswissenschaft an der Universität Freiburg und der University of Aberdeen, Schottland; 2009 Erste juristische Prüfung; Juristischer Vorbereitungsdienst des Landes Baden-Württemberg; 2011 Zweite juristische Staatsprüfung; Wissenschaftliche Mitarbeiterin am Institut für deutsches und ausländisches Zivilprozessrecht der Universität Freiburg; 2015 Promotion; derzeit Staatsanwältin bei der Staatsanwaltschaft Saarbrücken.

Jetzt bestellen:

https://mohrsiebeck.com/buch/die-entwicklung-der-rechtskraftlehre-im-franzoesischen-und-spanischen-recht9783161550881?no_cache $=1$

order@mohrsiebeck.com

Telefon: +49 (0)7071-923-17

Telefax: +49 (0)7071-51104 